\title{
Some notes on serendipity, the mind, and thinking
}

\author{
Tam-Tri Le \\ Centre for Interdisciplinary Social Research \\ Phenikaa University, Hanoi, Vietnam
}

3 December 2021

Here I briefly note down some points of extended discussions on serendipity, based on the original conceptual paper (Napier \& Vuong, 2013) as well as our team's recent arguments surrounding serendipity and thinking (Le, 2021; Nguyen, 2021).

I would like to thank Dr. Quan-Hoang Vuong for the insightful comments and inspiration.

From "If a tree falls in a forest and no one is around to hear it, does it make a sound?", we ask if an idea is formed in the brain but is not observed and recognized, does it make any impact? This reflects a core issue: we do not know how many times we have missed great ideas created by our own minds (serendipity moments).

The brain works continuously even when a person does not actively think (giving directions to the process - thinking - or demands to the result - thoughts). Even when actively thinking, one cannot fully track one's own thinking process. The brain can be seen as an automatic thought-factory that constantly produces. When awareness arises, some thoughts are selected for further evaluation, others are discarded due to having no or low perceived values; this follows the Mindsponge mechanism of information filtering (Nguyen et al., 2021; Vuong, 2016). In a normal condition, a large number of thoughts are discarded automatically throughout the day.

Many generated thoughts are automatically discarded due to the lack of awareness (observation). The loss itself is also not observed, thus we do not even know what happened. Active thinking has a higher degree of thought observation (motivated by the desire for results), however, this state does not last long (normally as a minor proportion of total awake time). In conditions of lower observation degree (e.g. shower thoughts), it is more likely to be hit or miss, but the exact influencing factors of hit probability are still unclear (consider the case of Archimedes).

During observation, the initial impressions of thoughts probably determine the prioritization of recognition. Think of lightning, the flashier ones are more observable, while those between clouds are mostly hidden. Ideas distract each other. It is also worth noting that due to the lack of careful evaluation at this initial point of observation, the less impressive idea may be actually more valuable and vice versa. This bias can be countered with a well-designed and objective system such as scientific recording.

Thinking and observing thoughts (being aware of thoughts) are two different types of mental processes. They happen in chronological order - thinking must finish (already produced a thought) before said thought can be observed (be known by oneself). Here I also argue that the process of thinking (to be clear, not its result - thought) cannot be directly observed because it 
does not hold information values (unlike thoughts). The awareness of thinking is, thereby, indirect (through other thoughts about the effects of the thinking process). Additionally, to further explore the relationship between thought and thought awareness, consider the dream state - where the brain constructs all components including the dream world, characters, and interactions, while the awareness is normally limited to a single perspective.

Upon complex problems, thinking can occur with high nonlinearity (simultaneous processing). Ideas formed during this time are highly abstract and new, thus are less comparable to stored reference information. This is particularly important when considering the heavy reliance of humans on sensory perceptions (making connections to tangible entities) and languages (serve as anchors for abstract concepts). Therefore, it is even harder to realize the value of such ideas. Here I also argue that while thinking varies in the degree of nonlinearity, thought observation requires a linear operation (or it would not make sense). This can be the key to exploring the issues of low awareness toward one's own thoughts in the context of creating the optimal conditions for capturing serendipity moments (Vuong \& Napier, 2014).

Update: More detailed discussions in the full book "A New Theory of Serendipity: Nature, Emergence and Mechanism" (see References).

\section{References}

Le, T.-T. (2021). Serendipity hints at a non-linear thinking mechanism [Preprint]. Open Science Framework. https://doi.org/10.31219/osf.io/gz7nd

Napier, N., \& Vuong, Q. H. (2013). Serendipity as a Strategic Advantage? In T. Wilkinson (Ed.), Strategic Management in the 21st Century (pp. 175-199). Praeger/ABC-Clio.

Nguyen, M.-H. (2021). Serendipity: The myth of delayed lightning strikes [Preprint]. Open Science Framework. https://doi.org/10.31219/osf.io/n2agy

Nguyen, M.-H., Vuong, Q. H., Ho, M.-T., \& Le, T.-T. (2021). Mindsponge mechanism (SSRN Scholarly Paper ID 3887262). Social Science Research Network. https://doi.org/10.2139/ssrn.3887262

Vuong, Q. H. (2016). Global Mindset as the Integration of Emerging Socio-Cultural Values Through Mindsponge Processes: A Transition Economy Perspective. In J. Kuada (Ed.), Global Mindsets: Exploration and Perspectives (pp. 109-126). Routledge. https://doi.org/10.4324/9781315736396-8

Vuong, Q. H., \& Napier, N. K. (2014). Making creativity: The value of multiple filters in the innovation process. International Journal of Transitions and Innovation Systems, 3(4), 294-327. https://doi.org/10.1504/IJTIS.2014.068306

Quan-Hoang Vuong. (2022). A New Theory of Serendipity: Nature, Emergence and Mechanism. Berlin, Germany: De Gruyter. 